\title{
Adrenergic stimulation alters the expression of inflammasome components and interleukins in primary human monocytes
}

\author{
JOHANN-PHILIPP HORSTMANN, INGO MARZI and BORNA RELJA \\ Department of Trauma, Hand and Reconstructive Surgery, University Hospital Frankfurt, \\ Goethe-University, Frankfurt 60590, Germany
}

Received March 4, 2015; Accepted September 28, 2015

DOI: 10.3892/etm.2015.2850

\begin{abstract}
Prior to their release, interleukin (IL)-1 $\beta$ and IL-18 are cleaved to their bioactive forms by a multiprotein complex known as an inflammasome, which is comprised of a number of elements that are subject to nuclear factor- $\kappa \mathrm{B}-$ dependent transcription. Catecholamines have been indicated to exert an enhancing effect on the IL- $1 \beta$ release. The aim of the present study was to determine whether alterations in inflammasome gene expression may be responsible for the modified IL-1 $\beta$ and IL-18 secretion following lipopolysaccharide (LPS) and catecholamine co-stimulation. Monocytes were isolated from the peripheral blood of 21 healthy volunteers using $\mathrm{CD} 14^{+}$ microbeads. Following stimulation with LPS $(2 \mu \mathrm{g} / \mathrm{ml})$ and/or phenylephrine (PE; $10 \mu \mathrm{M}$ ) for $24 \mathrm{~h}$, the supernatants were subjected to ELISA to evaluate the ex vivo protein expression levels of IL-1 $\beta$ and IL-18. In addition, the gene expression levels of inflammasome components associated with the cleavage of IL-1 $\beta$ and IL-18, including NLRP1, NLRP3, caspase-1 and PYCARD were determined using polymerase chain reaction. The results indicated that LPS significantly increased IL-1 $\beta$ expression compared with the unstimulated control samples. Co-stimulation with LPS + PE significantly enhanced IL-1 $\beta$ expression compared with LPS alone. Furthermore, IL-18 expression was significantly reduced by LPS and LPS + PE co-stimulation. The gene expression levels of IL-18, NLRP1, caspase-1 and PYCARD were comparable in the LPS- and LPS + PE-stimulated cells. LPS significantly induced the expression levels of IL-1 $\beta$ and NLRP3, and to a lesser degree, the expression of NLRP1, compared with the control. By contrast, PE markedly induced the expression levels of IL-18 and NLRP1, while LPS reduced the gene expression of IL-18. In conclusion, adrenergic stimulation suppressed NLRP3
\end{abstract}

Correspondence to: Dr Borna Relja, Department of Trauma, Hand and Reconstructive Surgery, University Hospital Frankfurt, Goethe-University, 7 Theodor-Stern-Kai, Frankfurt 60590, Germany E-mail: info@bornarelja.com

Key words: adrenergic effects, monocytes, inflammasome, NACHT, LRR and PYD domains-containing protein, interleukin-1 $\beta$, catecholamines expression and enhanced NLRP1 expression, indicating that NLRP3 may regulate IL-1 $\beta$ secretion and NLRP1 may regulate the release of IL-18.

\section{Introduction}

The extensively studied proinflammatory cytokine interleukin (IL)-1 $\beta$ is, among other humoral factors, a crucial mediator of the inflammatory response. IL-1 $\beta$ is secreted primarily by blood monocytes and macrophages, and is known to induce fever in the hypothalamic vascular network, facilitate neutrophil extravasation and bone marrow production, and induce IL-6 production (1). The dysregulation of IL-1 $\beta$ expression has been attributed to a number of systemic conditions, including familial Mediterranean fever, Muckle-Wells syndrome and diabetes mellitus type 2 (DMT2), while the inhibition of IL-1 $\beta$ expression has resulted in the mitigation of rheumatoid arthritis (RA), osteoarthritis and gout (2). IL-18 is an immunomodulatory cytokine that has been associated with a Th1-mediated immune reaction via the induction of interferon- $\gamma$. Furthermore, IL-18 has been associated with a number of autoinflammatory conditions, including systemic lupus erythematodes, Crohn's disease, psoriasis and graft-versus-host disease (3-5). In a previous mouse model of sepsis, animals with deletion or blockade of IL-18 had increased survival rates (6). IL-18 is thought to be expressed constitutively; however, the expression of IL-1 $\beta$ has to be induced by extracellular stimuli, such as damage-associated molecular pattern molecules or pathogen-associated molecular pattern molecules via toll-like receptor (TLR)-activation $(4,7)$.

Due to their highly relevant biological activities, IL-1 $\beta$ and IL-18 undergo tightly regulated intracellular processing. Prior to their secretion, IL-1 $\beta$ and IL-18 require the caspase-1-dependent cleavage and subsequent activation from their respective zymogen (pro-IL-1 $\beta$ and pro-IL-18) into bioactive forms $(4,5)$. The proteolytical activation of caspase- 1 is promoted by multiprotein complexes termed inflammasomes (8). The majority of known inflammasomes contain inactive caspase-1, in addition to the nucleotide-binding oligomerization domain, leucin-rich repeats and pyrin domain-containing protein (NLRP) and ultimately an apoptosis-associated speck-like protein containing a caspase recruitment domain (PYCARD) adaptor molecule (9). While the first described inflammasome was associated with NLRP1, the most extensively characterized inflammasome 
is NLRP3-containing (10). PYCARD is not essential to the NLRP1 inflammasome and is only necessary for the formation of NLRP3 inflammasomes; however, caspase-1 is obligatory and common to the majority of inflammasomes (9).

Adrenaline and noradrenaline are known as the prototypes of humoral stress signals, playing an important role as pharmaceutical agents for the treatment of anaphylaxis, asthma and for blood pressure control in intensive care medicine (11-15). The catecholamines adrenaline and noradrenaline were first purified by Takamine in 1901 and von Euler in 1946, respectively $(12,14,16)$. Additionally, there was increased interest in these catecholamines following the identification of their immunomodulating properties (17). In rheumatology, adrenergic stimulation has been associated with proinflammatory effects in acute diseases and anti-inflammatory effects in chronic diseases (18). Sympathetic activation, as induced by psychological stress, has been linked to chronic low-grade inflammatory diseases, such as DMT2, cardiovascular diseases, RA and the modulation of multiple sclerosis (19-21).

Previous studies that investigated the effect of catecholamines on human monocytes revealed an increase in the secretion of a number of proinflammatory cytokines, notably IL-1 $\beta$ (22,23). Grisanti et al (22) demonstrated that the application of phenylephrine (PE) increased the intracellular load of the $31-\mathrm{kD}$ progenitor pro-IL-1 $\beta$ and enhanced IL-1 $\beta$ protein expression in human monocytes. Previous studies have indicated that adrenergic stimulation induced p38 mitogen-activated protein kinase (MAPK) phosphorylation. Although IL-1 $\beta$ generation does not seem to require p38 MAPK activation, synergistic effects with the nuclear factor- $\kappa \mathrm{B}(\mathrm{NF}-\kappa \mathrm{B})$ pathway appear to be mediated via this signal in a number of contexts $(22,24)$. In addition to the gene expression of pro-IL-1 $\beta$, NLRP3 gene expression is induced by $\mathrm{NF}-\kappa \mathrm{B}$ activation $(25,26)$.

Although the IL-18 gene is speculated to be expressed constitutively, there have been conflicting results regarding the induction of IL-18 by TLR-dependent pathways. Certain results suggested that high mobility group box-1 administration stimulates pro-IL-18 synthesis via NF- $\kappa \mathrm{B}$ and $\mathrm{p} 38$ MAPK in THP-1 macrophages, while LPS-stimulation does not induce the expression of pro-IL-18 mRNA and protein in human primary peripheral blood mononuclear cells $(7,27)$.

The current pathophysiological understanding of the aforementioned chronic inflammatory diseases demonstrates the decisive role of inflammasomes. To the best of our knowledge, no prior study has investigated the extent to which the expression and activity of the inflammasomes is influenced by adrenergic stimuli. Furthermore, the IL-1 $\beta$ release in parallel with the IL-18 response has not previously been addressed within the context of adrenergic stimulation. Therefore, the aim of the present study was to determine whether the exposure of human primary monocytes to PE co-stimulated with LPS was able to: i) Further increase IL- $1 \beta$ secretion; ii) modulate the IL-18 response; and iii) alter the gene expression profile of inflammasome components.

\section{Materials and methods}

Ethical approval. This study was performed in the University Hospital Frankfurt, Goethe-University (Frankfurt, Germany) with the approval of the institutional ethics committee (no. 312/10, in accordance with the Declaration of Helsinki and following STROBE guidelines) (28). All healthy volunteers provided written informed consent in accordance with ethical standards. A total of 21 healthy volunteers (age range, 21-62 years) were enrolled in this study, including 11 men and 10 women, with a mean age of $31.9 \pm 11.7$ years.

Blood sampling. Peripheral blood samples $(9 \mathrm{ml})$ were obtained in ethylenediaminetetraacetic acid (EDTA) tubes (Sarstedt AG \& Co, Nürmbrecht, Germany) and stored at room temperature.

Monocyte purification. Monocytes from healthy volunteers were isolated from fresh blood samples using Ficoll density gradient centrifugation (Ficoll solution, $1.077 \mathrm{~g} / \mathrm{ml}$; Biochrom GmbH, Berlin, Germany) at $600 \mathrm{x} \mathrm{g}$ for $20 \mathrm{~min}$ at room temperature. Following the removal of the mononuclear cell layer, cells were washed twice in MACS buffer, containing $2 \mathrm{mM}$ EDTA (Sigma-Aldrich, St. Louis, MO, USA) and $0.5 \%$ bovine serum albumin (Sigma-Aldrich) in Dulbecco's phosphate-buffered saline without $\mathrm{Mg}^{2+}$ and $\mathrm{Ca}^{2+}$ (Gibco Thermo Fisher Scientific, Inc., Karlsruhe, Germany). Subsequently, monocytes were isolated by positive selection using anti-CD14-coated magnetic beads from Miltenyi Biotec (Bergisch Gladbach, Germany), according to the manufacturer's instructions. The purity of the isolated CD14 ${ }^{+}$cells $(>96 \%)$ was confirmed by flow cytometry (BD FACSCanto II; BD Biosciences, Heidelberg, Germany). Following their isolation, $\mathrm{CD}_{14}{ }^{+}$monocytes were immediately used for experiments. A total of $1 \times 10^{5}$ cells in $200 \mu \mathrm{l}$ RPMI-1640 (Biochrom GmbH) were seeded in 48-well plates (BD Biosciences, Franklin Lakes, NJ, USA) supplemented with $10 \%$ heat-inactivated fetal calf serum, $100 \mathrm{IU} / \mathrm{ml}$ penicillin and $100 \mu \mathrm{g} / \mathrm{ml}$ streptomycin (Gibco; Thermo Fisher Scientific, Inc.) and $20 \mathrm{mM}$ HEPES buffer (Sigma-Aldrich) and adhered for $1 \mathrm{~h}$ at $37^{\circ} \mathrm{C}$ in humidified $5 \% \mathrm{CO}_{2}$. Subsequently, nonadherent cells were removed and adherent cells were washed and recultured in $200 \mu 1$ RPMI-1640 (with supplements) as described earlier.

Cell stimulation and ex vivo cytokine expression assay. The cells were divided into four groups and stimulated as follows: LPS group, $2 \mu \mathrm{g} / \mathrm{ml}$ LPS from Escherichia coli 0127:B8 (Sigma-Aldrich); PE group, $10 \mu \mathrm{M}$ PE (E4250; Sigma-Aldrich); LPS + PE group, combination of LPS and PE treatment at the aforementioned doses; and control (ctrl) group, untreated. After incubation for $24 \mathrm{~h}$, the supernatants were removed by manual pipetting, stored at $-80^{\circ} \mathrm{C}$ and subsequently assayed for IL-1 $\beta$ and IL-18 expression using a Human IL-1 $\beta /$ IL-1F2 Quantikine ${ }^{\circledR}$ ELISA kit (R\&D Systems, Inc., Minneapolis, MN, USA) and a Human IL-18 ELISA kit (MBL International Corporation, Woburn, MA, USA), according to the manufacturer's instructions.

$R N A$ isolation and semi-quantitative reverse transcription polymerase chain reaction (RT-PCR). Following the stimulation of $\mathrm{CD}_{14}{ }^{+}$monocytes for $24 \mathrm{~h}$, total RNA was isolated using an RNeasy kit (Qiagen, Hilden, Germany) according to the manufacturer's instructions. Residual DNA was removed using an RNase-free DNase kit (Qiagen). The quality and quantity of RNA were determined photometrically using a NanoDrop 1000 
A

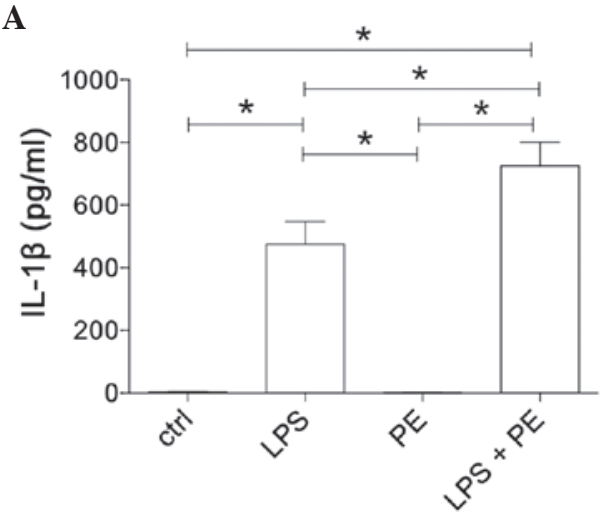

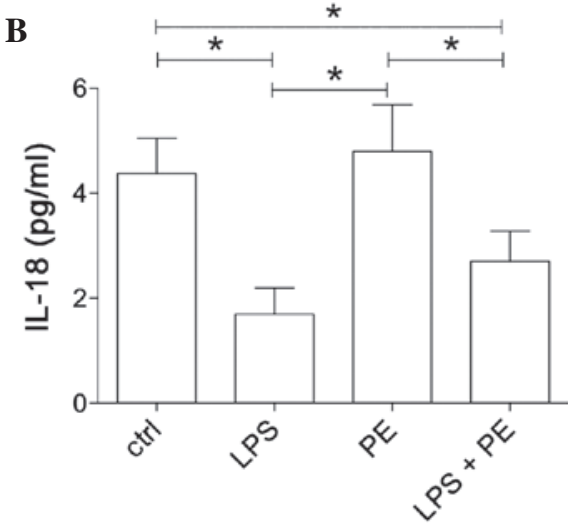

Figure 1. LPS and/or PE stimulation induced distinct IL-1 $\beta$ and IL-18 expression in CD14+ monocytes isolated from peripheral mononuclear blood cells, by positive selection using CD14-magnetic beads. Cells from healthy volunteers $(n=21)$ were stimulated with LPS and/or PE. Supernatants were collected after $24 \mathrm{~h}$ and the protein expression of (A) IL-1 $\beta$ and (B) IL-18 was measured by enzyme-linked immunosorbent assay. Data are presented as the mean \pm standard error of the mean. "P<0.05. IL-1 $\beta$, interleukin-1 $\beta$; ctrl, control; LPS, lipopolysaccharide; PE, phenyephrine; IL-18, interleukin-18.

spectrophotometer (NanoDrop Technologies, Wilmington, DE, USA). RNA was subsequently reverse transcribed using an AffinityScript cDNA Synthesis kit (Agilent Technologies, Waldbronn, Germany) and subjected to semi-quantitative RT-PCR, as described previously (29). To determine the mRNA expression levels of NLRP1, NLRP3, IL-1 $\beta$, IL-18, caspase-1 and PYCARD, an Mx3005P qPCR system (Agilent Technologies) was used with gene-specific primers for human NLRP1 (GenBank no. NM_033004; UniGene no. Hs.652273; cat. no. PPH06155E), NLRP3 (GenBank no. NM_183395; UniGene no. Hs.159483; cat. no. PPH13170A), IL-1 $\beta$ (GenBank no.NM_000576; UniGene no.Hs.126256; cat.no.PPH00171B), IL-18 (GenBank no. NM_001562.2; UniGene no. Hs.83077; cat. no. PPH00580C), CASP1 (GenBank no. NM_033292; UniGene no. Hs.2490; cat. no. PPH00105B) and PYCARD (GenBank no. NM_013258; UniGene no. Hs.499094; cat. no. PPH00907A) that were purchased from SABiosciences (Frederick, MD, USA). Human glyceraldehyde 3-phosphate dehydrogenase (GAPDH; GenBank no. NM_002046; UniGene no. Hs.592355; cat. no. PPH00150E; SABiosciences) was assayed as the reference gene. PCR was conducted using a 1X RT² SYBR Green/Rox qPCR Master Mix (SABiosciences) in a total volume of $25 \mu \mathrm{l}$, according to the manufacturer's instructions. A two-step amplification protocol was conducted, as follows: Initial denaturation at $95^{\circ} \mathrm{C}$ for $10 \mathrm{~min}$, followed by 40 cycles of $15 \mathrm{sec}$ denaturation at $95^{\circ} \mathrm{C}$ and $60 \mathrm{sec}$ annealing/extension at $60^{\circ} \mathrm{C}$. The specificity of amplification products was controlled using the melting-curve analysis. Relative expression of target mRNA in each sample was calculated using the comparative threshold-cycle $(\mathrm{Ct})$ method $(\Delta \Delta \mathrm{Ct})$ method, as described previously (30). The quantity of target mRNA in each sample was normalized against that of GAPDH mRNA in order to determine $\Delta \mathrm{Ct}$, and then against the quantity of a calibrator consisting of $\Delta \mathrm{Ct}$ from unstimulated cells (ctrl group). Relative gene expression is presented as a fold change compared with the ctrl. Methods of monocyte purification, seeding and sampling were similar in design to a previous study (31).

Statistical analysis. GraphPad Prism software, version 6.0 (GraphPad Software Inc., La Jolla, CA, USA) was used to perform the statistical analysis. Normality of all data was verified by the Kolmogorov-Smirnov test. Data are presented as the mean \pm standard error of the mean. One-way analysis of variance with a Dunn post-hoc test were used for comparison among the different groups. $\mathrm{P}<0.05$ was considered to indicate a statistically significant difference.

\section{Results}

LPS and PE response in $\mathrm{CD}_{14}{ }^{+}$monocytes. To determine the monocyte function following adrenergic (PE) and LPS stimulation, the ex vivo IL-1 $\beta$ and IL-18 expression in the isolated $\mathrm{CD} 14^{+}$monocytes was measured by ELISA. IL-1 $\beta$ expression was significantly increased following LPS stimulation compared with that in the untreated ctrl (475.1 \pm 73.0 vs. $3.8 \pm 1.7 \mathrm{pg} / \mathrm{ml} ; \mathrm{P}<0.05$; Fig. 1A). The administration of $\mathrm{PE}$ alone had no effect on IL-1 $\beta$ expression compared with that of the unstimulated ctrl $(1.2 \pm 1.1$ vs. $3.8 \pm 1.7 \mathrm{pg} / \mathrm{ml}$; Fig. 1A). However, treatment with LPS + PE significantly increased IL-1 $\beta$ expression compared with all other treatments $[725.8 \pm 75.8$ vs. 3.8 \pm 1.7 (ctrl), $475.1 \pm 73.0$ (LPS) and $1.2 \pm 1.1 \mathrm{pg} / \mathrm{ml}(\mathrm{PE}) ; \mathrm{P}<0.05$; Fig. $1 \mathrm{~A}]$.

IL-18 expression was significantly decreased by LPS stimulation compared with that of the untreated ctrl $(1.7 \pm 0.5$ vs. $4.4 \pm 0.7 \mathrm{pg} / \mathrm{ml}$; P<0.05; Fig. 1B). Stimulating monocytes with PE did not significantly alter IL-18 expression compared with the unstimulated ctrl ( $4.8 \pm 0.9$ vs. $4.4 \pm 0.7 \mathrm{pg} / \mathrm{ml}$; Fig. 1B). However, the combination treatment of monocytes with LPS + PE significantly reduced IL-18 expression compared with that in the untreated ctrl and PE-stimulated cells $[2.7 \pm 0.6$ vs. $4.4 \pm 0.7$ (ctrl) and $4.8 \pm 0.9 \mathrm{pg} / \mathrm{ml}(\mathrm{PE}) ; \mathrm{P}<0.05$; Fig. 1B] and showed a tendency to reverse the LPS-induced IL-18 suppression; however, this effect was not statistically significant (Fig. 1B).

Effect of LPS and PE on the gene expression of inflammasome components. To elucidate the basal expression characteristics of NLRP1 and NLRP3 inflammasome components following LPS and/or PE stimulation in parallel to the inflammasome functionality, gene expression analyses of all involved inflammasome components were performed in $\mathrm{CD} 14^{+}$monocytes 

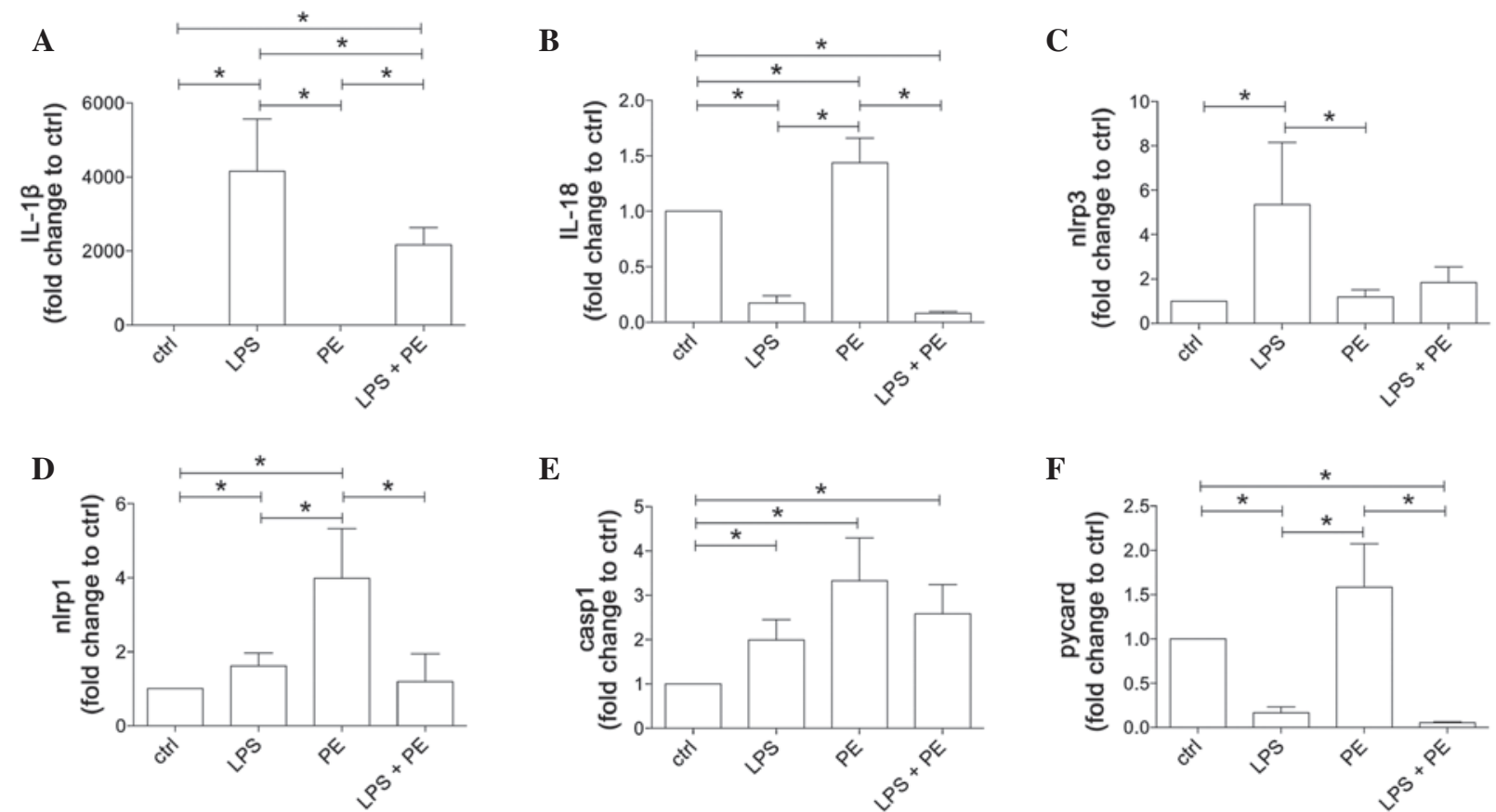

Figure 2. LPS and/or PE stimulation results in distinct gene expression pattern of inflammasome components in CD14 ${ }^{+}$monocytes, which were isolated from peripheral mononuclear blood cells from healthy volunteers $(n=21)$ by positive selection using CD14-magnetic beads. Cells were stimulated with LPS and/or PE and the gene expression levels (A) IL- $\beta$, (B) IL-18, (C) NLRP3, (D) NLRP1, (E) caspase-1 and (F) PYCARD were measured. Data are shown as the mean \pm standard error of the mean. "P $<0.05$. IL, interleukin; LPS, lipopolysaccharide; PE, phenylephrine; NLRP, NACHT, LRR and PYD domains-containing protein; casp1, caspase-1; PYCARD, apoptosis-associated speck-like protein containing a caspase recruitment domain.

from healthy volunteers following LPS and/or PE stimulation (Fig. 2).

The gene expression of the IL-1 $\beta$ precursor was notably induced as a result of LPS stimulation (4,151.0 $\pm 1,417.0$-fold vs. ctrl) compared with the unstimulated ctrl and PE-stimulated monocytes $(1.9 \pm 0.8$-fold vs. ctrl; $\mathrm{P}<0.05$; Fig. $2 \mathrm{~A})$. PE treatment did not change IL- $1 \beta$ gene expression compared with ctrl. Co-stimulation of monocytes with LPS + PE significantly enhanced IL-1 $\beta$ gene expression compared with the expression of the ctrl or PE-treated cells; however, LPS + PE led to significantly reduced values compared with those in the cells treated with LPS alone $[2,170.0 \pm 461.0$-fold (LPS + PE) vs. $1.9 \pm 0.8$-fold (PE) or 4,151.0 $\pm 1,417.0$-fold (LPS) change against the ctrl; $\mathrm{P}<0.05$; Fig. 2A].

IL-18 gene expression was significantly enhanced in the PE-stimulated cells compared with that in the ctrl, LPSor LPS + PE-stimulated samples [1.4 \pm 0.2 -fold (PE) vs. $0.2 \pm 0.06$-fold (LPS) and $0.1 \pm 0.01$-fold (LPS + PE) change against the ctrl; $\mathrm{P}<0.05$; Fig. 2B]. By contrast, IL-18 expression was markedly reduced in the LPS- and LPS + PE-stimulated cells compared with the ctrl cells.

The expression of NLRP3 was significantly increased in the LPS-stimulated cells compared with the ctrl and all other groups [5.4 \pm 2.7 -fold (LPS) vs. 1.2 \pm 0.3 -fold (PE) and $1.8 \pm 0.7$-fold (LPS + PE) change against the ctrl; $\mathrm{P}<0.05$; Fig. 2C).

Stimulation of $\mathrm{CD} 14^{+}$monocytes with LPS or PE significantly increased NLRP1 gene expression compared with the untreated ctrl $(\mathrm{P}<0.05$, Fig. 2D). However, PE-induced NLRP1 expression was markedly enhanced compared with all other groups $(\mathrm{P}<0.05)$, while LPS $+\mathrm{PE}$ decreased NLRP1

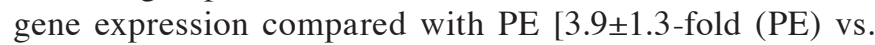

$1.6 \pm 0.3$-fold (LPS) and 1.2 \pm 0.7 -fold (LPS + PE) change against the ctrl; $\mathrm{P}<0.05$; Fig. 2D).

The expression of caspase-1 precursor was significantly increased in all stimulated groups compared with the untreated ctrl $(\mathrm{P}<0.05)$; however, there were no statistically significant differences between the stimulation groups (Fig. 2E).

The expression of PYCARD was decreased in the LPSand LPS + PE-stimulated cells compared with the ctrl cells; however, stimulation with PE alone led to a nonsignificant increase in PYCARD mRNA expression compared with the ctrl cells (Fig. 2F). Furthermore, the expression of PYCARD was significantly increased in the PE-stimulated cells compared with the LPS and LPS + PE groups $[1.6 \pm 0.5$-fold (PE) vs. $0.2 \pm 0.07$-fold (LPS) and $0.1 \pm 0.01$-fold (LPS + PE) change against the ctrl; $\mathrm{P}<0.05$; Fig. 2F).

\section{Discussion}

Inflammasomes are intracellular molecular multiprotein platforms that are responsible for the caspase-1-mediated cleavage of pro-IL-1 $\beta$ and pro-IL-18 into their active IL-1 $\beta$ and IL-18 forms. The relevance of inflammasomes in a number of autoimmune diseases has been described previously (32); however, little is currently known about the possible effects of 'stress signals', such as endogenous or clinically administered catecholamines, on inflammasome expression and activation.

The results of the present study indicated a potent and distinct effect of catecholamines on inflammation-induced inflammasome activation. Although LPS was proven to be an effective inflammasome activator as demonstrated by increased IL-1 $\beta$ expression, PE alone did not induce any effects on the IL-1 $\beta$ expression. However, the co-stimulation 
of monocytes with LPS + PE significantly potentiated the LPS-induced IL-1 $\beta$ expression (Fig. 1A). These findings are consistent with the results of Grisanti et al (22), which presented increased levels of supernatant IL- $1 \beta$ in primary human monocytes co-stimulated with LPS + PE compared with LPS-stimulation alone, results which may be associated with increased p38 MAPK activity. However, in contrast to the observed increase in pro-IL-1 $\beta$ concentration within the cytosol in Gristanti et al (22), the gene expression levels of IL-1 $\beta$ were reduced in the present study. These data indicate that the enhancing effects of PE co-stimulation on IL- $1 \beta$ secretion following LPS application may occur on a post-genomic level, possibly as a result of increased IL-1 $\beta$ mRNA stability, as has been described previously for p38 MAPK activation $(33,34)$. However, the present study and the prior study by Grisanti et al (22) indicate that PE-stimulation alone does not stimulate IL-1 $\beta$ expression in human primary monocytes.

Regarding IL-18, the results of the present study were unexpected. LPS treatment reduced the gene expression and secretion of the constitutively low-expressed IL-18, and while PE alone did not seem to have any effect on IL-18 secretion, it appeared to partly restore IL-18 secretion following LPS application. However, this trend was not statistically significant (Fig. 1B). There is consistency between the IL-18 gene transcription and protein expression levels observed in the present study and the results of Puren et al (7), who identified no increase in pro-IL-18 protein expression following LPS stimulation, and a reduction in pro-IL-18 mRNA expression after $24 \mathrm{~h}$ of LPS exposure. In order to account for the nonsignificant increase in IL-18-secretion detected following co-stimulation with LPS + PE compared with LPS alone, we hypothesize a compensatory effect, mediated by PE, which may involve increased inflammasome activity or pro-IL-18 mRNA stability.

The evaluation of IL-1 $\beta$ and IL-18 expression may be used as an indicator of inflammasome activity. Previous studies have suggested that LPS alone may not be a sufficient stimulus for the secretion of IL-1 $\beta$ and inflammasome activation in primary human monocytes, and have identified ATP binding to $\mathrm{P} 2 \mathrm{X} 7$ receptor as a necessary secondary signal $(4,35)$. However, recent studies observed stable IL-1 $\beta$ responses and inflammasome activation in response to LPS stimulation alone (36-38). The inflammasome activation and subsequent expression of IL-1 $\beta$ and IL-18 is dependent on intracellularly available components, which are required for inflammasome assembly (39). According to the present results, the gene expression of NLRP1 may be enhanced by PE alone in the absence of TLR or interleukin receptor stimulation. This may elucidate the role of NLRs in chronic, stress-induced, sterile inflammatory diseases, such as DMT2, RA or multiple sclerosis. Notably, co-stimulation with PE negated the positive effects of LPS on the gene expression levels of NLRP3. In previous experiments by the present authors (31), a reduction in NLRP3 gene expression was observed in patients suffering polytrauma (unpublished data). It remains unclear whether a surge in endogenous or administered circulating catecholamines following trauma may mediate this phenomenon. The present results indicate that adrenergic stimulation on human monocytes may lead to the suppression of NLRP3 and enhancement of NLRP1 inflammasome gene expression. Furthermore, a qualitative comparison of the zymogen and NLR gene expression patterns observed may support the hypothesis that IL-1 $\beta$ secretion is mediated by the NLRP3 inflammasome, as IL-18 appears to be associated with NLRP1 activity.

However, considering the secretion of inflammasome dependent cytokines and the expression profile of associated genes following LPS and/or PE application, the effects of adrenergic stimulation on monocytes cannot be exclusively attributed to a modification of gene expression, but appear to involve an unclear post-genomic regulation. Notably, the present results do not support the hypothesis of genomic mechanisms underlying the marked increase of IL-1 $\beta$ secretion following co-stimulation with LPS + PE compared with LPS alone, as none of the analyzed constituents of the secretory mechanism presented further mRNA upregulation. Further studies are required to determine whether there is an interaction at a post-genomic level. Although there is an evident potential therapeutic interest associated with the study of neuroimmunologic interactions, the present and previous studies demonstrate the complexity of these processes. As the network of associations between catecholamines and cytokines is currently without an adequate model, further studies are required.

\section{Acknowledgements}

The authors thank Kerstin Kontradowitz, Katrin Jurida and Alexander Schaible for their technical assistance, and Dr Dirk Henrich for his intellectual contribution to the study (Department of Trauma, Hand and Reconstructive Surgery, University Hospital Frankfurt, Goethe-University, Frankfurt, Germany).

\section{References}

1. Dinarello CA: Interleukin-1beta. Crit Care Med 33 (Suppl 12): S460-S462, 2005.

2. Dinarello CA: A clinical perspective of IL-1 $\beta$ as the gatekeeper of inflammation. Eur J Immunol 41: 1203-1217, 2011.

3. Boraschi D and Dinarello CA: IL-18 in autoimmunity: Review. Eur Cytokine Netw 17: 224-252, 2006.

4. Dinarello CA: Immunological and inflammatory functions of the interleukin-1 family. Annu Rev Immunol 27: 519-550, 2009.

5. Lebel-Binay S, Berger A, Zinzindohoué F, Cugnenc $\mathrm{PH}$ Thiounn N, Fridman WH and Pagès F: Interleukin-18: Biological properties and clinical implications. Eur Cytokine Netw 11: 15-26, 2000.

6. Dinarello CA and Fantuzzi G: Interleukin-18 and host defense against infection. J Infect Dis 187 (Suppl 2): S370-S384, 2003.

7. Puren AJ, Fantuzzi G and Dinarello CA: Gene expression, synthesis and secretion of interleukin 18 and interleukin 1beta are differentially regulated in human blood mononuclear cells and mouse spleen cells. Proc Natl Acad Sci USA 96: 2256-2261, 1999.

8. Martinon F, Burns K and Tschopp J: The inflammasome: A molecular platform triggering activation of inflammatory caspases and processing of proIL-beta. Mol Cell 10: 417-426, 2002.

9. Schroder K and Tschopp J: The inflammasomes. Cell 140: 821-832, 2010.

10. Dagenais M, Skeldon A and Saleh M: The inflammasome: In memory of Dr. Jurg Tschopp. Cell Death Differ 19: 5-12, 2012.

11. Arnold JJ and Williams PM: Anaphylaxis: Recognition and management. Am Fam Physician 84: 1111-1118, 2011.

12. Bennett MR: One hundred years of adrenaline: The discovery of autoreceptors. Clin Auton Res 9: 145-159, 1999.

13. Donohue JF and Ohar JA: New combination therapies for asthma. Curr Opin Pulm Med 7: 62-68, 2001. 
14. von Euler US: Visceral functions of the nervous system. Annu Rev Physiol 16: 349-370, 1954.

15. Giraud R, Siegenthaler N, Arroyo D and Bendjelid K: Impact of epinephrine and norepinephrine on two dynamic indices in a porcine hemorrhagic shock model. J Trauma Acute Care Surg 77: 564-569, quiz 650-651, 2014.

16. Yamashima T: Jokichi Takamine (1854-1922), the samurai chemist, and his work on adrenalin. J Med Biogr 11: 95-102, 2003.

17. Grisanti LA, Perez DM and Porter JE: Modulation of immune cell function by $\alpha(1)$-adrenergic receptor activation. Curr Top Membr 67: 113-138, 2011.

18. Straub RH, Bijlsma JW, Masi A and Cutolo M: Role of neuroendocrine and neuroimmune mechanisms in chronic inflammatory rheumatic diseases-the 10-year update. Semin Arthritis Rheum 43: 392-404, 2013.

19. Cosentino M and Marino F: Adrenergic and dopaminergic modulation of immunity in multiple sclerosis: Teaching old drugs new tricks? J Neuroimmune Pharmacol 8: 163-179, 2013

20. Black PH: The inflammatory consequences of psychologic stress: Relationship to insulin resistance, obesity, atherosclerosis and diabetes mellitus, type II. Med Hypotheses 67: 879-891, 2006.

21. Capellino S, Cosentino M, Wolff C, Schmidt M, Grifka J and Straub RH: Catecholamine-producing cells in the synovial tissue during arthritis: Modulation of sympathetic neurotransmitters as new therapeutic target. Ann Rheum Dis 69: 1853-1860, 2010.

22. Grisanti LA, Woster AP, Dahlman J, Sauter ER, Combs CK and Porter JE: $\alpha 1$-Adrenergic receptors positively regulate toll- like receptor cytokine production from human monocytes and macrophages. J Pharmacol Exp Ther 338: 648-657, 2011.

23. Johnson JD, Campisi J, Sharkey CM, Kennedy SL, Nickerson M, Greenwood BN and Fleshner M: Catecholamines mediate stress-induced increases in peripheral and central inflammatory cytokines. Neuroscience 135: 1295-1307, 2005

24. Guha M and Mackman N: LPS induction of gene expression in human monocytes. Cell Signal 13: 85-94, 2001.

25. Bauernfeind FG, Horvath G, Stutz A, Alnemri ES, MacDonald K, Speert D, Fernandes-Alnemri T, Wu J, Monks BG, Fitzgerald KA, et al: Cutting edge: NF-kappaB activating pattern recognition and cytokine receptors license NLRP3 inflammasome activation by regulating NLRP3 expression. J Immunol 183: 787-791, 2009.

26. Takeuchi $O$ and Akira S: Pattern recognition receptors and inflammation. Cell 140: 805-820, 2010.
27. He Q, You H, Li XM, Liu TH, Wang P and Wang BE: HMGB1 promotes the synthesis of pro-IL-1 $\beta$ and pro-IL-18 by activation of p38 MAPK and NF- $\mathrm{BB}$ through receptors for advanced glycation end-products in macrophages. Asian Pac J Cancer Prev 13: 1365-1370, 2012.

28. Von Elm E, Altman DG, Egger M, Pocock SJ, Gøtzsche PC and Vandenbroucke JP; STROBE Initiative: The strengthening the reporting of observational studies in epidemiology (STROBE) statement: Guidelines for reporting observational studies. J Clin Epidemiol 61: 344-349, 2008.

29. Relja B, Höhn C, Bormann F, Seyboth K, Henrich D, Marzi I and Lehnert M: Acute alcohol intoxication reduces mortality, inflammatory responses and hepatic injury after haemorrhage and resuscitation in vivo. Br J Pharmacol 165: 1188-1199, 2012.

30. Schmittgen TD and Livak KJ: Analyzing real-time PCR data by the comparative C(T) method. Nat Protoc 3: 1101-1108, 2008

31. Relja B, Hortstmann JP, Kintradowitz K, Jurida K, Schaible A, Neunaber C, Oppermann E and Marzi I: Nlrp1 inflammasome is downregulated in trauma patients. J Mol Med (Berl): Aug 2, 2015 (Epub ahead of print).

32. Martinon F, Mayor A and Tschopp J: The infammasomes: Guardians of the body. Annu Rev Immunol 27: 229-265, 2009.

33. Chen YL, Huang YL, Lin NY, Chen HC, Chiu WC and Chang CJ: Differential regulation of ARE-mediated TNFalpha and IL-1beta mRNA stability by lipopolysaccharide in RAW264.7 cells. Biochem Biophys Res Commun 346: 160-168, 2006.

34. Sirenko OI, Lofquist AK, DeMaria CT, Morris JS, Brewer G and Haskill JS: Adhesion-dependent regulation of an A+U-rich element-binding activity associated with AUF1. Mol Cell Biol 17: 3898-3906, 1997.

35. Mariathasan S and Monack DM: Inflammasome adaptors and sensors: Intracellular regulators of infection and inflammation. Nat Rev Immunol 7: 31-40, 2007.

36. Chen S and Sun B: Negative regulation of NLRP3 inflammasome signaling. Protein Cell 4: 251-258, 2013.

37. He Y, Franchi L and Núñez G: TLR agonists stimulate Nlrp3-dependent IL-1 $\beta$ production independently of the purinergic $\mathrm{P} 2 \mathrm{X} 7$ receptor in dendritic cells and in vivo. J Immunol 190: 334-339, 2013.

38. Netea MG, Nold-Petry CA, Nold MF, Joosten LA, Opitz B, van der Meer JH, van de Veerdonk FL, Ferwerda G, Heinhuis B, Devesa I, et al: Differential requirement for the activation of the inflammasome for processing and release of IL-1beta in monocytes and macrophages. Blood 113: 2324-2335, 2009.

39. Latz E, Xiao TS and Stutz A: Activation and regulation of the inflammasomes. Nat Rev Immunol 13: 397-411, 2013. 